Research Article

\title{
Experimental Study on the Mechanical Property of Loess Mixed with Bentonite-HDTMA
}

\author{
Zhang Ming $\mathbb{D}^{1}{ }^{1}$ Chen Guozhou, ${ }^{2}$ Liu Yang, ${ }^{3}$ and Huang Shouhai ${ }^{4}$ \\ ${ }^{1}$ Hengzhou University of Aeronautics, Zhengzhou, China \\ ${ }^{2}$ Henan Urban Planning Institute and Corporation, Zhengzhou, China \\ ${ }^{3}$ Zhongyun International Engineering Co., Ltd., Zhengzhou, China \\ ${ }^{4}$ Henan Zhongtian Zecheng Detection and Research Institute Co., Ltd., Xingyang, China \\ Correspondence should be addressed to Zhang Ming; zhangming@zua.edu.cn
}

Received 11 November 2021; Accepted 19 November 2021; Published 6 December 2021

Academic Editor: Bingxiang yuan

Copyright $\odot 2021$ Zhang Ming et al. This is an open access article distributed under the Creative Commons Attribution License, which permits unrestricted use, distribution, and reproduction in any medium, provided the original work is properly cited.

\begin{abstract}
Malan loess in the middle and lower reaches of the Yellow River after mixed with different bentonite and HDTMA ratios was selected to carry out shear and consolidation tests for discussing the influence of bentonite-HDTMA on the mechanical property of loess lining material in landfills. Studies have shown that, after mixing $6 \%$ to $14 \%$ bentonite, the cohesive force of modified loess is significantly increased, the friction angle is reduced and remains stable, and the shear strength is improved. The compressibility of materials slightly decreases with the increase of bentonite ratio. The addition of $2 \%-4 \%$ HDTMA weakens the increment for the cohesive force caused by bentonite, but the friction angle is effectively recovered. The compressibility of materials increases with the increase of HDTMA ratio. As the dry density increases, the shear strength of the modified loess increases, and the compressibility coefficient decreases. The mechanical property of loess lining material can be optimized by adding $6 \%-14 \%$ bentonite. The incorporation of $2 \%-4 \%$ HDTMA does not have a significant negative impact on the optimization effect of bentonite. From the perspective of the mechanical property, it is recommended that the dry density of modified loess is $1.70 \mathrm{~g} / \mathrm{cm}^{3}$, the bentonite ratio is $10 \%-14 \%$, and the HDTMA ratio is $2 \%-4 \%$.
\end{abstract}

\section{Introduction}

Sanitary landfill is one of the final disposal methods of solid waste, as shown in Figure 1. Landfills need to be lined to intercept pollutants including heavy metals, organic compounds, and pathogens [1-3]. Traditionally, clay is used as a lining material for solid waste disposal [4-6]. However, clay material is lacking, and loess is widely distributed in the middle and lower reaches of the Yellow River, and the permeability coefficient of loess after compaction is usually greater than $1.0 \times 10^{-7} \mathrm{~cm} / \mathrm{s}$ [7], which does not meet the requirement of lining materials for seepage prevention.

Studies have shown that modified bentonite can be used as an alternative lining for landfills [8-10]. The modified objects of bentonite abroad are mainly general soils such as cohesive soil and sandy soil. When the bentonite ratio is less than $15 \%$, the technical requirement of permeability coefficient of less than $10^{-7} \mathrm{~cm} / \mathrm{s}$ can be met. Chinese scholars have carried out research on the permeability of loess mixed with bentonite in the northwest region in China. Zhang et al. [11] studied the change of permeability coefficient of Lanzhou loess and Yulin loess mixed with bentonite and found that the permeability coefficient of loess was lower than $1.0 \times 10^{-7} \mathrm{~cm} / \mathrm{s}$ after adding $14 \%$ and $10 \%$ of bentonite, respectively. Liu et al. [12] tested the permeability coefficient of the loess-bentonite mixture in Beijing area. The results show that the water content of $2 \%$ greater than the optimal water content is selected for compaction, and the permeability coefficient is $9 \times 10^{-8} \mathrm{~cm} / \mathrm{s}$. However, loess modified by bentonite has a limited adsorption capacity for pollutants. It is found in the field of water pollution treatment that the soil after adding appropriate HDTMA (cationic surfactant, hexadecyltrimethylammonium bromide) can not only maintain low permeability but also absorb more 


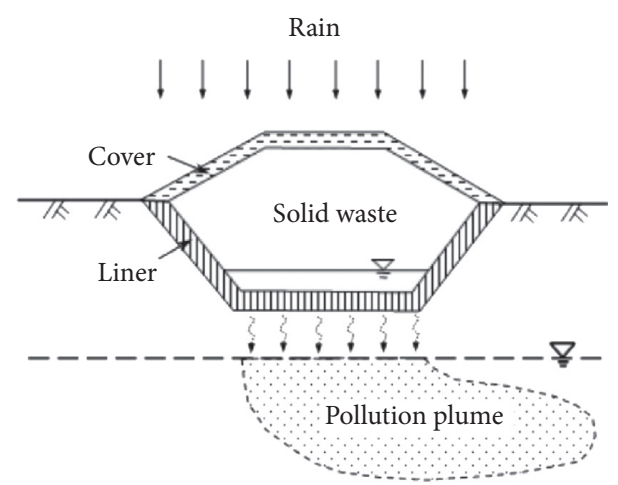

Figure 1: Conceptual drawing of the solid waste disposal landfill.

organic pollutants $[13,14]$. From the perspective of environmental science, loess modified by bentonite-HDTMA can be used as a lining material for solid waste landfills.

Due to the undulating terrain and the puncture of hard objects, the lining structure of the landfill will bear shear stress during the service period, and the shear strength must be considered in the design. In addition, the slow consolidation and deformation occur for the lining structure as its own weight and the upper solid waste weight $[15,16]$. How and whether the consolidation process will affect its antiseepage performance are the concern of the disposal project. Therefore, the shear strength and consolidation properties of loess modified by bentonite-HDTMA directly affect its engineering application prospects. This is a key basic indicator for judging whether the selection of lining materials is reasonable. In this paper, the shear and compression test of bentonite-HDTMA-modified loess were carried out by the direct shear and consolidation instrument, and the influence of bentonite-HDTMA on the mechanical property of the material was investigated. The optimal bentonite/ HDTMA ratio for modified loess as a lining material was proposed. It is expected to provide basic research data for the localization of lining materials in loess areas and serve the ecological protection and high-quality development of the middle and lower reaches of the Yellow River.

\section{Materials and Methods}

2.1. Materials. The loess used in the test is Malan loess in Sanmenxia area of Henan province, with a depth of 1.0-3.0 m in the site. The basic physical properties are shown in Table 1. The soil sample is brownish yellow with uniform texture. Undisturbed loess is characterized by a high content of fine particles and the plasticity index of 8.5 , which is a typical silty soil. Bentonite for the test was purchased from Fumaying, Shandong. The basic physical properties are shown in Table 1. HDTMA in the test has a purity of $99 \%$ and was purchased from Beijing Yinuokai Technology Co., Ltd.

The loess is mixed with the weight ratio of $0 \%-14 \%$ bentonite and 0\%-2\% HDTMA, respectively, distilled water is added by spraying to make the sample evenly humidified according to the predetermined moisture content, and it is placed in a humidifier for $60 \mathrm{~h}$. The TYA-3000 electrohydraulic servo compression testing machine is used to gradually apply a load to the soil sample at a loading speed of $2 \mathrm{kN} / \mathrm{s}$. After the final load is loaded, the sample is fully loaded for 10 minutes. Finally, the sample is slowly pushed out by the demoulding machine to prepare the test. The basic parameters of the samples are shown in Table 2.

2.2. Test Method. The ZJ-type strain-controlled direct shear apparatus of Nanjing Soil Instrument Factory is used for the shear test. The compacted sample is cut into the ring cutter with a diameter of $61.8 \mathrm{~mm}$ and a height of $20 \mathrm{~mm}$, and then the sample is pushed from the ring cutter into the direct shear tester for direct shear test. A shear load at a rate of $0.8 \mathrm{~mm} / \mathrm{min}$ is applied, and the reading of the force gauge is recorded. If the reading of the dynamometer is stable or there is a significant retreat, it means that the sample has been sheared and damaged, and the peak value is taken as the shear strength value. If the dynamometer reading continues to increase, the test should be stopped when the shear deformation reaches $6 \mathrm{~mm}$, and the shear stress corresponding to the shear strain $4 \mathrm{~mm}$ is taken as the shear strength value. The 4 samples of each group of the direct shear test are applied with a vertical pressure of $100,200,300$, and $400 \mathrm{kPa}$, respectively. The test process is carried out in strict compliance with the China code [17].

The PPS electrical consolidation instrument of Beijing Huakan Technology Co., Ltd., is used for the consolidation test. The sample is hard, and the initial applied pressure is set as $25 \mathrm{kPa}$; referring to the ultimate bearing capacity of garbage [18], the upper limit of the applied pressure of the consolidation test is set as $600 \mathrm{kPa}$, and the intermediate pressure is $50,100,200$, and $400 \mathrm{kPa}$, respectively. After the vertical pressure is applied, the vertical deformation is recorded every 1 hour. When the consolidation deformation is not more than $0.005 \mathrm{~mm} / \mathrm{h}$, the consolidation deformation of the sample is considered stable. The test is also carried out in accordance with the China code [17].

\section{Results}

\subsection{Shear Test Results}

3.1.1. The Influence of Bentonite Ratio on Shear Strength. Figure 2 shows the relationship between the shear strength of the modified loess and the normal stress, the dry density is 
TABLE 1: Basic physical properties of materials in the test.

\begin{tabular}{lccccccc}
\hline \multirow{2}{*}{ Sample } & \multicolumn{3}{c}{ Particle percentage } & \multicolumn{3}{c}{ Liquid limit (\%) } & \multirow{2}{*}{ Plastic limit (\%) } \\
& $0.25-0.075 \mathrm{~mm}$ & $0.075-0.05 \mathrm{~mm}$ & $0.05-0.01 \mathrm{~mm}$ & $0.01-0.005 \mathrm{~mm}$ & $<0.005 \mathrm{~mm}$ & \\
\hline Malan loess & 1.9 & 38.5 & 31.1 & 5.7 & 22.8 & 25.9 & 17.4 \\
Bentonite & 2.4 & 16.1 & 17.8 & 13.3 & 50.4 & 78.3 & 41.3 \\
\hline
\end{tabular}

TABLE 2: The basic parameters of samples.

\begin{tabular}{|c|c|c|c|c|c|}
\hline Sample no. & Bentonite ratio (\%) & HDTMA ratio (\%) & Water content (\%) & Gravity & Dry density $\left(\mathrm{g} / \mathrm{cm}^{3}\right)$ \\
\hline M1 & 10 & 2 & 19.3 & 2.71 & 1.35 \\
\hline M2 & 10 & 2 & 19.3 & 2.71 & 1.54 \\
\hline M3 & 10 & 2 & 17.8 & 2.71 & 1.70 \\
\hline M4 & 6 & 2 & 17.1 & 2.70 & 1.68 \\
\hline M5 & 14 & 2 & 18.4 & 2.71 & 1.68 \\
\hline M6 & 10 & 0 & 17.4 & 2.70 & 1.69 \\
\hline M7 & 10 & 4 & 17.5 & 2.71 & 1.68 \\
\hline M8 & 0 & 0 & 18.5 & 2.70 & 1.70 \\
\hline M9 & 100 & 0 & 20.8 & 2.74 & 1.65 \\
\hline
\end{tabular}

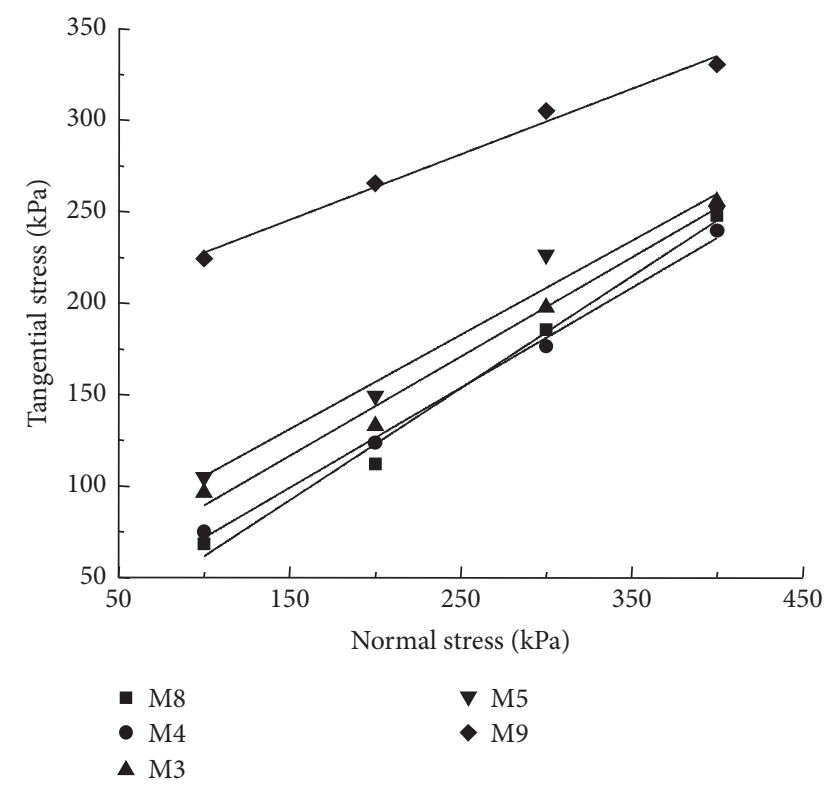

Figure 2: Curves of shear strength-normal stress.

$1.70 \mathrm{~g} / \mathrm{cm}^{3}$, and the HDTMA ratio is $2 \%$ (standard compacted maximum dry density [19]). The bentonite ratio is $6 \%-14 \%$. As the bentonite ratio increases, the shear strength gradually increases. According to the Coulomb shear theory, the relationship between shear strength $(\tau)$ and normal stress $(\sigma)$ is

$$
\tau=c+\sigma \tan \varphi
$$

In the formula, $c$ is the cohesive force, and $\varphi$ is the internal friction angle.

Formula ( 1 ) is used to fit the data in Figure 2 by least square method linear regression to obtain the equation, shown in Table 3. Compared with pure loess (M8), the bentonite ratio is $6 \%-14 \%(\mathrm{M} 3, \mathrm{M} 4$, and M5), and the shear strength of the material is enhanced, but still less than pure bentonite (M9). As the bentonite ratio increases, the cohesive force gradually increases: when the bentonite ratio is $6 \%$, the cohesive force is $17.0 \mathrm{kPa}$; when the bentonite ratio is $14 \%$, the cohesion increased to $56.8 \mathrm{kPa}$. The cohesive force of pure loess is only $0.3 \mathrm{kPa}$. It can be known that the cohesive force of M3, M4, and M5 is provided by bentonite. When the bentonite ratio differs, the internal friction angle of the mixture changes very little: when the bentonite ratio is increased from $6 \%$ to $14 \%$, the internal friction angle is reduced from $28.6^{\circ}$ to $27.2^{\circ}$, and the difference is only $1.4^{\circ}$. For the loess, it contains larger coarse particles. The addition of bentonite can reduce the permeability of the soil, also improve the workability for the lining material, and improve the shear strength of the loess.

3.1.2. The Influence of HDTMA Ratio on Shear Strength. Figure 3 shows the relationship between shear strength and normal stress of modified loess, the dry density is $1.70 \mathrm{~g} / \mathrm{cm}^{3}$, and the bentonite ratio is $10 \%$. The HDTMA ratio ranges from $0 \%$ to $4 \%$, and the curve equation is fitted according to the Coulomb shear theory, shown in Table 4 . It can be found from the fitting equation that the cohesive force of the modified loess decreases from $52.2 \mathrm{kPa}$ (M6) to 35.1 (M3) and $36.7 \mathrm{kPa}(\mathrm{M} 7)$ as the HDTMA ratio increases from $0 \%$ to $4 \%$ (M3, M6, and M7), and the internal friction angle increases from $14.7^{\circ}$ (M6) to $24.1^{\circ}-28.5^{\circ}$. When the HDTMA ratio is $2 \%-4 \%$, the shear strength of the modified loess is basically stable. It can be known that adding a small amount of HDTMA can effectively alleviate the downward trend of the internal friction angle of the modified loess.

3.1.3. The Influence of Dry Density on Shear Strength. Figure 4 is the relationship between the shear strength of modified loess and the normal stress with the same bentonite and HDTMA ratio. The dry density range is $1.35-1.70 \mathrm{~g} / \mathrm{cm}^{3}$, including the curve fitted according to the Coulomb shear theory. The fitting equation is shown in Table 5. It can be known from the fitting equation that, as the dry density 
TABLE 3: Regression equation of shear strength for loess modified by different bentonite ratios.

\begin{tabular}{lccc}
\hline Sample no. & Loess-bentonite-HDTMA mass ratio & Fitting formula & $R^{2}$ \\
\hline M8 & $100-0-0$ & $\tau=0.3+\sigma \tan 31.5^{\circ}$ & 0.9862 \\
M4 & $100-6-2$ & $\tau=17.0+\sigma \tan 28.6^{\circ}$ & 0.9946 \\
M3 & $100-10-2$ & $\tau=35.1+\sigma \tan 28.5^{\circ}$ & 0.9822 \\
M5 & $100-14-2$ & $\tau=56.8+\sigma \tan 27.2^{\circ}$ & 0.9657 \\
M9 & $0-100-0$ & $\tau=191.7+\sigma \tan 19.7^{\circ}$ & 0.9836 \\
\hline
\end{tabular}

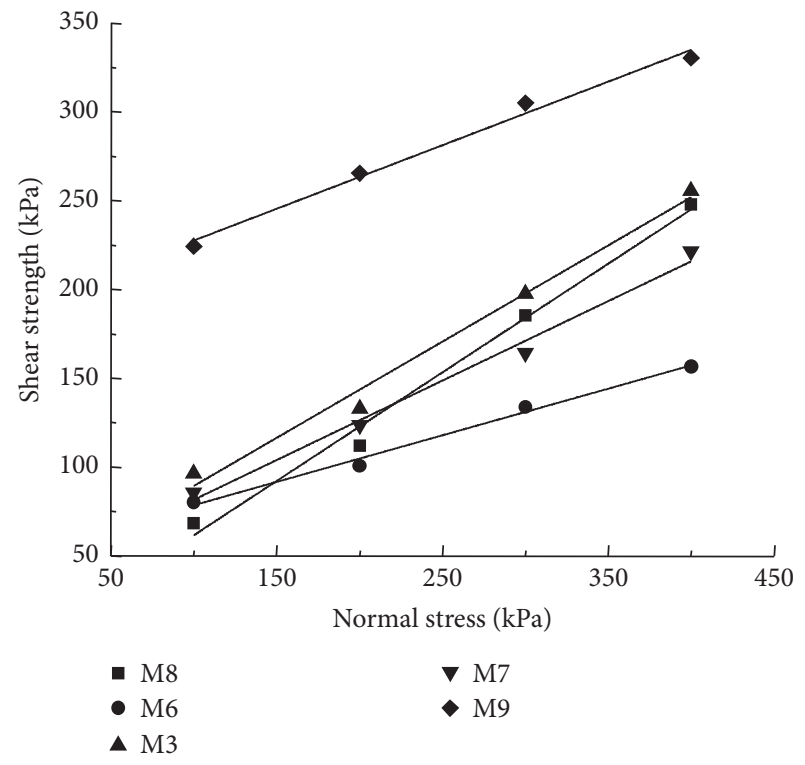

FIgURE 3: Curves of shear strength-normal stress.

increases from 1.35 to $1.70 \mathrm{~g} / \mathrm{cm}^{3}$, the cohesive force increases from $17.4 \mathrm{kPa}(\mathrm{M} 1)$ to $35.1 \mathrm{kPa}(\mathrm{M} 3)$, and the internal friction angle increases from $25.4^{\circ}$ to $28.5^{\circ}$. The dry density increases, the void ratio of material decreases, and the contact points of the soil increase, so the connection of the fine-grained soil is strengthened, and the internal friction angle of the coarse-grained soil increases. On the whole, the shear strength of the modified loess increases with the increase in dry density. The compaction test shows that the maximum dry density of the modified loess is about $1.70 \mathrm{~g} /$ $\mathrm{cm}^{3}$ [19], and the shear strength of M3 and M6 can be used as the basis for engineering practice design.

\subsection{Consolidation Test Results}

3.2.1. The Influence of Bentonite Ratio on the Compressibility. Figure 5 is the $e-\log \sigma$ curve of modified loess with the dry density of $1.70 \mathrm{~g} / \mathrm{cm}^{3}$ and the HDTMA ratio of $2 \%$. The bentonite ratio ranges from $6 \%$ to $14 \%$. It can be known that the initial void ratio of the sample increases with the increase of bentonite ratio, which is consistent with the test results of Maio et al. [20]. As the axial stress increases, the void ratio of the sample decreases nonlinearly. The sample transitions from the elastic state to the plastic state, the curve has a bilinear characteristic, and the distance between the curves does not change significantly. According to the China code [17], the compressibility coefficient $a_{1-2}$ obtained by $\sigma_{1}=100 \mathrm{kPa}$ and $\sigma_{2}=200 \mathrm{kPa}$ is used as the index for evaluating the soil compressibility. The calculation shows that the compressibility coefficients of loess modified by $6 \%$, $10 \%$, and $14 \%$ of bentonite are $0.25,0.23$, and 0.21 , respectively, which all belonged to the moderately compressible soils. It can be known that, as the bentonite ratio increases from $6 \%$ to $14 \%$, the compressibility coefficient decreases slightly. For all samples, as the axial stress increases from $25 \mathrm{kPa}$ to $600 \mathrm{kPa}$, the compressibility coefficient decreases, and when the axial stress is greater than $400 \mathrm{kPa}$, the compressibility coefficient of the sample under different axial stresses basically remains unchanged. The test results show that, after adding bentonite, the ability of modified loess to resist the deformation caused by the upper load is enhanced.

\subsubsection{The Influence of HDTMA Ratio on the Compressibility.} Figure 6 is the $e$ - $\log \sigma$ curve of modified loess with the dry density of $1.70 \mathrm{~g} / \mathrm{cm}^{3}$ and the bentonite ratio of $10 \%$, and the HDTMA ratio is $0 \%-4 \%$. It can be found from Figure 6 that the initial void ratio of the sample increases with the increase of HDTMA ratio. As the axial stress increases, the void ratio of the sample decreases nonlinearly, and the compression curve intersects between 400 and $500 \mathrm{kPa}$. As HDTMA increases, the slope of the curve increases. The calculation result shows that $a_{1-2}$ with $0 \%, 2 \%$, and 4\% HDTMA ratios is $0.21,0.23$, and 0.31 , respectively, and the samples all belonged to moderately compressible soils. As the HDTMA ratio increases, the compressibility coefficient increases slightly. For all samples, the compressibility coefficient decreases with the increase of axial stress from $25 \mathrm{kPa}$ to $600 \mathrm{kPa}$. The compressibility coefficient of the samples remains unchanged when the axial stress is greater than $400 \mathrm{kPa}$. With the same upper load, the compaction potential of the modified loess mixed with HDTMA is greater, and the increment of dry density leads to the enhancement of its antiseepage performance.

3.2.3. The Influence of Dry Density on the Compressibility. Figure 7 is the $e$ - $\log \sigma$ curve of modified loess with $10 \%$ bentonite and 2\% HDTMA. The dry density is in the range of $1.35-1.70 \mathrm{~g} / \mathrm{cm}^{3}$. Generally, the compression curve also shows bilinear characteristics. As the axial stress increases, the curves gradually fit closer; that is, the control effect of dry density on the compression curve becomes weaker and weaker in the high-stress range. This is consistent with the experimental conclusions obtained by Sun et al. [21] on the deformation characteristics of unsaturated bentonite under confined stress. This is mainly because the soil void ratio 
TABLE 4: Regression equation of shear strength for loess modified by different HDTMA ratios.

\begin{tabular}{lccc}
\hline Sample no. & Loess-bentonite-HDTMA mass ratio & Fitting formula & $R^{2}$ \\
\hline M8 & $100-0-0$ & $\tau=0.3+\sigma \tan 31.5^{\circ}$ & 0.9862 \\
M6 & $100-10-0$ & $\tau=52.2+\sigma \tan 14.7^{\circ}$ & 0.9883 \\
M3 & $100-10-2$ & $\tau=35.1+\sigma \tan 28.5^{\circ}$ & 0.9822 \\
M7 & $100-10-4$ & $\tau=36.7+\sigma \tan 24.1^{\circ}$ & 0.9853 \\
M9 & $0-100-0$ & $\tau=191.7+\sigma \tan 19.7^{\circ}$ & 0.9836 \\
\hline
\end{tabular}

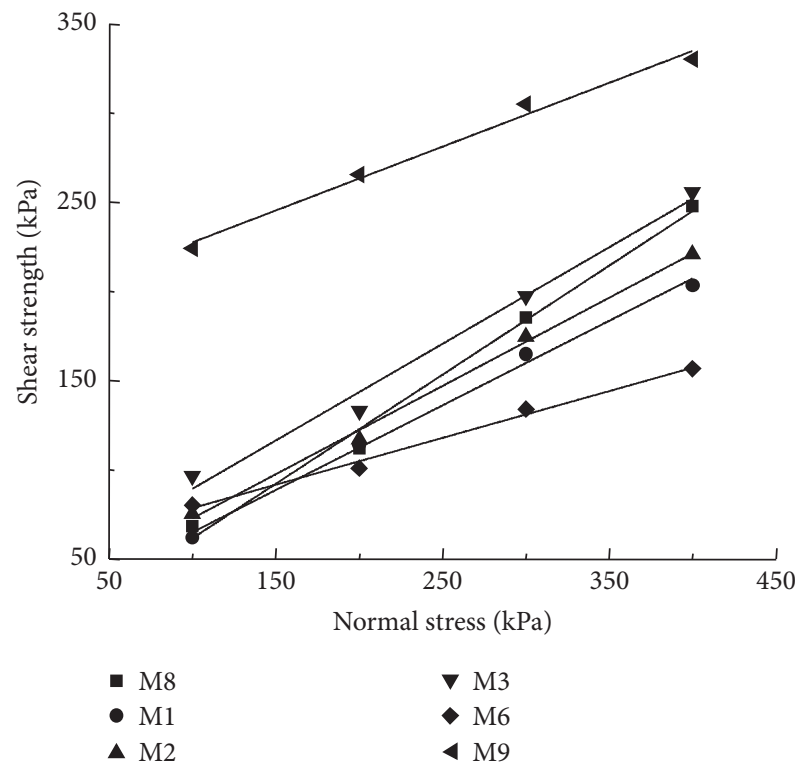

Figure 4: Curves of shear strength-normal stress.

decreases and the soil particles are arranged more closely as the dry density increases. On the one hand, the soil particle contact area increases, resulting in an increase in internal friction; on the other hand, the soil particle spacing becomes smaller, and the skeleton structure is more stable. This makes the relative displacement resistance of the soil particles increase and the compression more difficult. The test results show that $a_{1-2}$ of M1, M2, and M3 is $0.53,0.29$, and $0.23 \mathrm{MPa}^{-1}$, respectively. M1 belongs to high compressibility soil, and the other samples belong to medium compressibility soil.

\section{Discussion}

(1) The ability of the sample to resist shear deformation is determined by the material composition and structure of the modified loess. Cohesion force and internal friction angle are the strength indicators of soil resistance to shear failure. Without considering the cohesion of the soil, the shear strength is mainly determined by the internal friction, including the relative sliding resistance between soil particles, the rolling resistance, and the bite force formed by the interengagement of soil particles [22, 23]. When the soil particles on the upper and lower parts of the shear surface move, the bite force must be overcome first, and then the frictional resistance between the particles plays a major role. The coarser the soil particles are, the longer and steeper the slope needs to climb caused by overcoming the bite force and the greater the shear stress required. Loess has less finegrain content and cohesion force $(0.3 \mathrm{kPa})$, so the internal friction angle is the decisive factor for the shear strength of loess.

Bentonite has small particles and contains more hydrophilic minerals. The particles are mainly connected by bound water and can also be connected by cement or weak capillary. Its shear strength is mainly determined by the bond strength between particles. When loess is mixed with less than $14 \%$ bentonite, fine clay particles can fill the pores of coarse silt particles. As shown in Figure 8, after adding $10 \%$ bentonite (Figure $8(\mathrm{~b})$ ), the pores of the coarse loess particles are fined by the clay, and the pores are fully filled. The material particle gradation is optimized, and the distance and angle of the climbing slope will be reduced when the particles bite together and move laterally. The force required to overcome the bite force to climb the slope is decreased when the soil resists the shear deformation, and the internal friction angle is reduced; at the same time, part of the shear strength begins to be borne by cohesion.

In addition, as shown in Figure 8(c), the clarity of the clay sheet structure is weakened after adding HDTMA, which may be caused by the HDTMA organic chain coating on the surface of the clay particles [24]. The tendency of smooth transition leads to a decrease in the cohesive force of the soil; HDTMA, as an organic cation, exchanges with the exchangeable cations between the layers of clay particles [25, 26], forming agglomerated structures, and the contact area between the agglomerates is greater and closer, so the internal friction angle increases.

(2) The moisture content of samples M1-M9 is $17.1 \%$ $20.8 \%$, and the initial saturation is $53.0 \%-84.0 \%$. During the compression test, the moisture content remains unchanged, the material void ratio decreases, and the saturation of the modified loess sample increases. It can be considered that the compression test is a process in which the sample gradually develops from unsaturated compression to a saturated state. In the mesolevel, the consolidation of the modified loess sample first destroys the large 
TABLE 5: Regression equation of shear strength for loess modified by different dry densities.

\begin{tabular}{lccc}
\hline Sample no. & Loess-bentonite-HDTMA mass ratio & Fitting formula & $R^{2}$ \\
\hline M8 & $100-0-0$ & $\tau=0.3+\sigma \tan 31.5^{\circ}$ & 0.9862 \\
M1 & $100-10-2$ & $\tau=17.4+\sigma \tan 25.4^{\circ}$ & 0.9930 \\
M2 & $100-10-2$ & $\tau=23.2+\sigma \tan 26.3^{\circ}$ & 0.9951 \\
M3 & $100-10-2$ & $\tau=35.1+\sigma \tan 28.5^{\circ}$ & 0.9822 \\
M6 & $100-10-0$ & $\tau=52.2+\sigma \tan 14.7^{\circ}$ & 0.9883 \\
M9 & $0-100-0$ & $\tau=191.7+\sigma \tan 19.7^{\circ}$ & 0.9836 \\
\hline
\end{tabular}

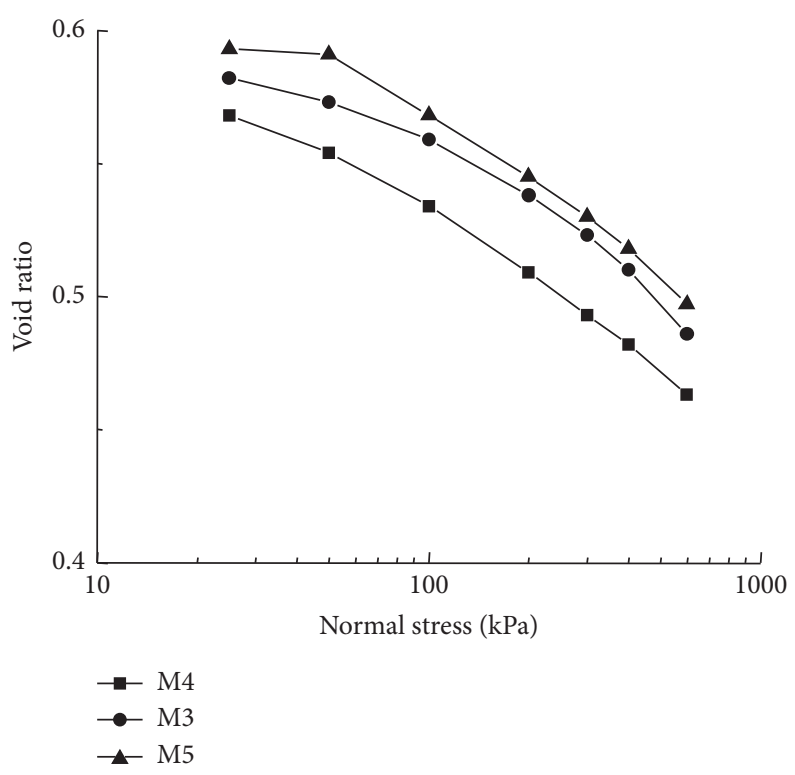

FIgURE 5: Compression curves of modified loess with different bentonite ratios.

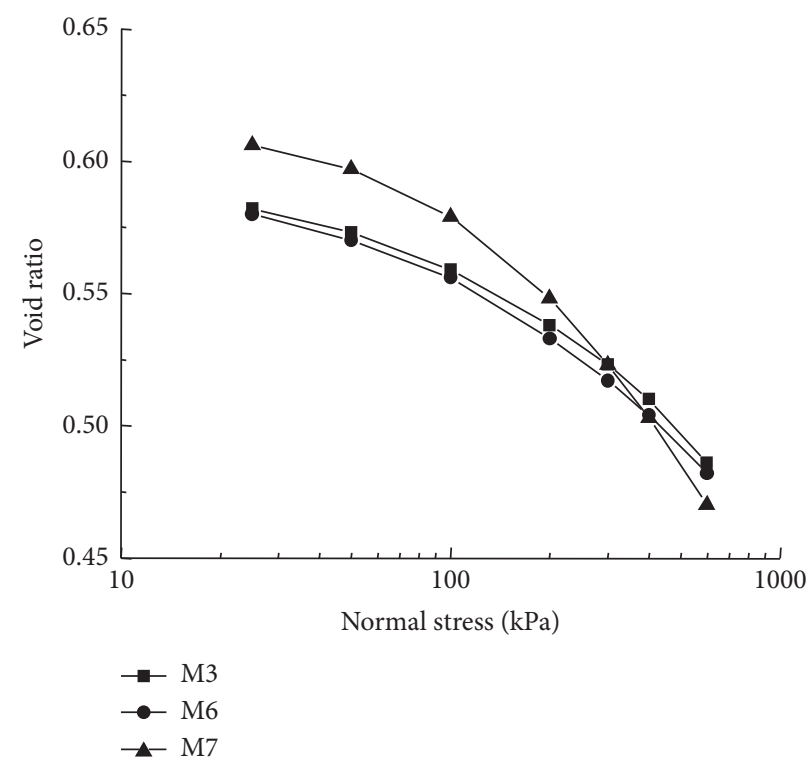

Figure 6: Compression curves of modified loess with different HDTMA ratios. 


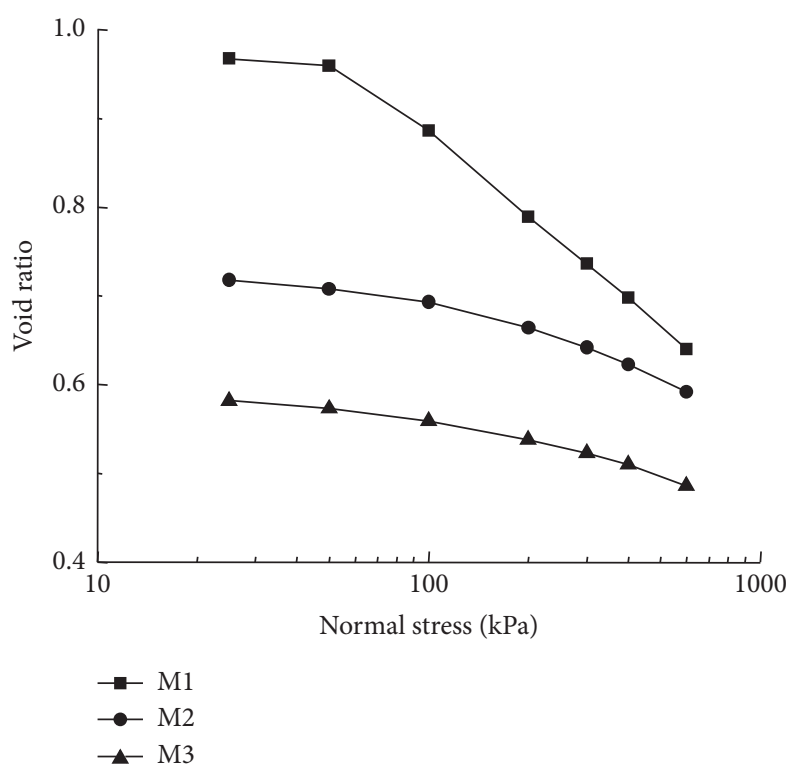

Figure 7: Compression curves of modified loess with different dry densities.

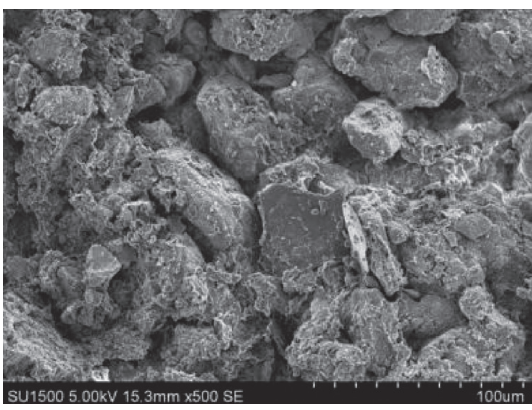

(a)

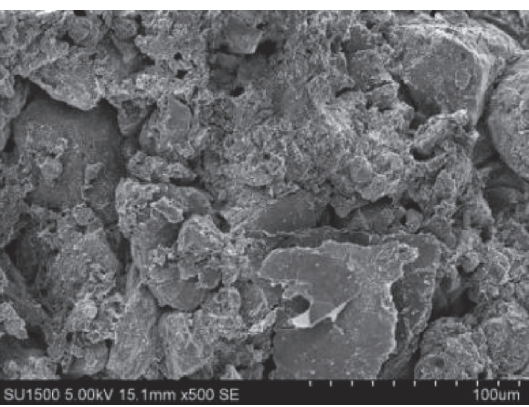

(b)

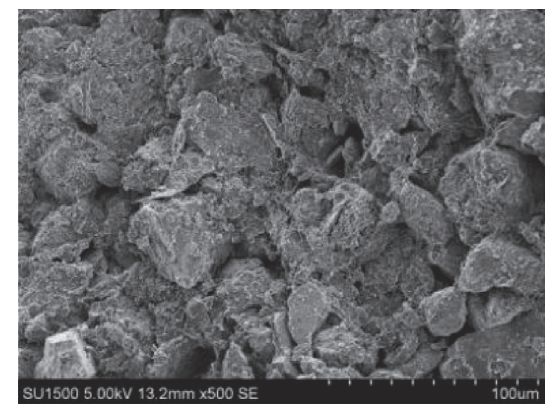

(c)

Figure 8: 500-time SEM of modified loess. (a) Malan loess. (b) Malan loess $+10 \%$ bentonite. (c) Malan loess $+10 \%$ bentonite $+2 \%$ HDTMA.

overhead pores [27, 28]; at this time, the large overhead pores are transformed into other small pore types due to the damage of the loess grain frame. As the vertical stress increases, the hollow pores begin to be destroyed. The vertical stress continues to increase, and small overhead pores begin to break and form mosaic pores. The mosaic pores are relatively stable. The subsequent strain is only the rotational orientation distribution of particles, which has little effect on the change of pores [29-31].

Figure 9 is a schematic diagram of the pore structure change mode of the modified loess sample during the consolidation process. There was no significant decrease in void ratio in this test. Therefore, it is believed that the modified loess samples only suffered damage to the large and medium frame pores under the condition of vertical stress below $600 \mathrm{kPa}$. The compression curve of this test should be close to the upper limb curve at the initial stress stage, that is, the compression curve in the unsaturated

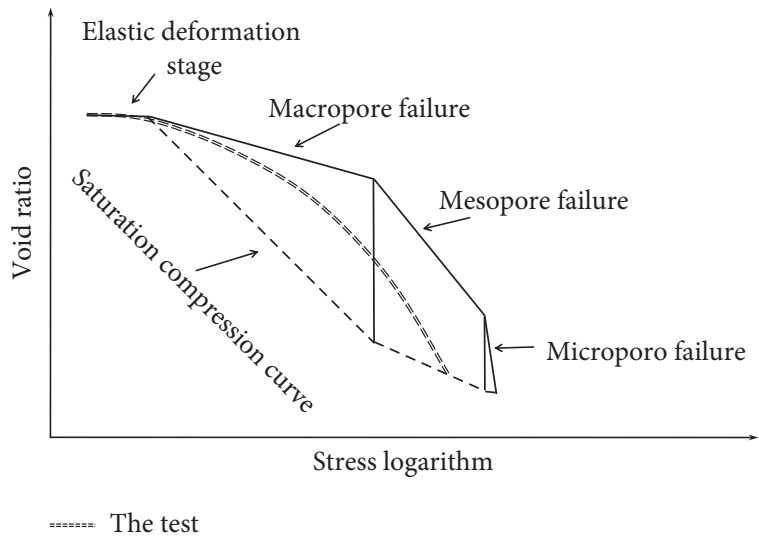

FIgURE 9: Pore failure modes of the loess in the compression test (redrawn document [29]).

state; the compression curve should be close to the compression curve in the saturated state under the condition of high stress. 


\section{Conclusions}

Malan loess in Sanmenxia area of Henan province is selected and mixed with different bentonite and HDTMA ratios to carry out direct shear test and consolidation test, explore the effect of bentonite-HDTMA on the mechanical property of loess, and propose suitable bentonite and HDTMA ratio for loess lining materials in the middle and lower reaches of the Yellow River. The conclusions are as follows.

The shear strength of Malan loess in the middle and lower reaches of the Yellow River is mainly contributed by the internal friction angle. Pores between coarse grains of loess can be effectively filled by $6 \%-14 \%$ bentonite. Mixing bentonite improves the shear strength of the material and reduces the material compressibility. The addition of bentonite can optimize the mechanical property of the modified loess lining material.

The addition of $2 \%-4 \%$ HDTMA weakens the increase in the cohesive force of modified loess caused by bentonite, but the internal friction angle of the material is effectively restored, and the shear strength of the material remains basically unchanged; the compression coefficient of modified loess increases, and the lining structure of the disposal site has the potential to further improve the antiseepage performance during the service period.

As the dry density increases, the shear strength and compressive properties of the bentonite-HDTMA-modified loess will increase. It is recommended that the dry density of the modified loess lining material should be $1.70 \mathrm{~g} / \mathrm{cm}^{3}$, the bentonite ratio should be $10 \%-14 \%$, and the HDTMA ratio should be $2 \%-4 \%$ under the standard compaction condition.

\section{Data Availability}

The data used to support the findings of this study are available from the corresponding author upon request.

\section{Conflicts of Interest}

The authors declare that they have no conflicts of interest.

\section{Acknowledgments}

This research was funded by the 2021 Scientific and Technological Project in Henan Province (Grant no. 212102310968), Henan Educational Committee (Grant no. 21A410004), and Henan Department of Housing and Urban Rural Construction (Grant no. HNJS-2020-K25).

\section{References}

[1] W. Prabuddhi, A. K. Pabasari, T. C. Asitha, S. S. Lam, B. C. L. Athapattu, and M. Vithanage, "Progress and prospects in mitigation of landfill leachate pollution: risk, pollution potential, treatment and challenges," Journal of Hazardous Materials, vol. 421, Article ID 126627, 2022.

[2] O. Felix, G. Emmanuel, K. A. Emmanuel, F. O. Agyemang, and K. Mensah-Darkwa, "Stabilization of heavy metals in soil and leachate at Dompoase landfill site in Ghana," Environmental Challenges, vol. 5, Article ID 100308, 2021.
[3] B. Bai, R. Zhou, G. Cai, W. Hu, and G. Yang, "Coupled thermo-hydro-mechanical mechanism in view of the soil particle rearrangement of granular thermodynamics," Computers and Geotechnics, vol. 137, no. 8, Article ID 104272, 2021.

[4] MOHURD, Technical Code for Municipal Solid Waste Sanitary Landfill, China Architecture \& Building Press, Beijing, China, 2013.

[5] R. Arjwech, K. Somchat, P. Pondthai, M. Everett, M. Schulmeister, and S. Saengchomphu, "Assessment of geological, hydrogeological and geotechnical characteristics of a proposed waste disposal site: a case study in Khon Kaen, Thailand," Geosciences, vol. 10, p. 109, 2020.

[6] B. Bai, Q. K. Nie, Y. Zhang, X. Wang, and W. Hu, "Cotransport of heavy metals and $\mathrm{SiO}_{2}$ particles at different temperatures by seepage," Journal of Hydrology, vol. 597, Article ID 125771, 2021.

[7] X. Li, J. Y. Liu, Z. Z. Guo et al., "Study on relationship between pore structure parameters and permeability of Malan loess," Journal of Engineering Geology, vol. 128, pp. 10-18, 2018.

[8] D. Koch, "Bentonites as a basic material for technical base liners and site encapsulation cut-off walls," Applied Clay Science, vol. 21, pp. 1-11, 2002.

[9] Q. Tang, K. Takeshi, I. Toru, and Z. Li, "Membrane behavior of bentonite-amended compacted clay," Soils and Foundations, vol. 54, pp. 329-344, 2014.

[10] Y. L. Loretta, H. J. Zhang, G. Tamer, and J. R. Grace, "Effect of polybrominated diphenyl ethers on sand-bentonite liner material," Waste Management, vol. 89, pp. 73-82, 2019.

[11] H. Y. Zhang, T. Y. Zhao, J. R. Wu et al., "Laboratory measurement and prediction to the permeability of bentonitemodified loess as a landfill liner," Rock and Soil Mechanics, vol. 32, pp. 1963-1974, 2011.

[12] Y. S. Liu, Q. Z. Bai, and Y. F. Nie, "Properties of bentonite enhanced loess and laterite," Chinese Journal of Chemical Engineering, vol. 1, pp. 43-47, 2004.

[13] M. C. Irene, K. M. Raymond, and C. H. Samuel, "Modified clays for waste containment and pollutant attenuation," Journal of Environmental Engineering, vol. 123, pp. 25-32, 1997.

[14] G. P. Agnieszka, M. Marek, P. Stanisław, and D. Sternik, "Simultaneous adsorption of chromium(VI) and phenol on natural red clay modified by HDTMA," Chemical Engineering Journal, vol. 179, pp. 140-150, 2012.

[15] B. Bai, G. C. Yang, T. Li, and G. S. Yang, "A thermodynamic constitutive model with temperature effect based on particle rearrangement for geomaterials," Mechanics of Materials, vol. 139, Article ID 103180, 2019.

[16] B. X. Yuan, Z. H. Li, Y. M. Chen et al., "Mechanical and microstructural properties of recycling granite residual soil reinforced with glass fiber and liquid-modified polyvinyl alcohol polymer," Chemosphere, vol. 268, Article ID 131652, 2021.

[17] MOHURD, Standard for Geotechnical Testing Method, China Planning Press, Beijing, China, 2019.

[18] Y. H. Cheng, S. G. Hu, and H. Chen, "Study on deformation characteristics of refuse landfill based on large-scale plate loading test," Chinese Journal of Rock Mechanics and Engineering, vol. 39, pp. 3076-3084, 2020.

[19] H. Q. Zhu, M. Zhang, and Y. C. Du, "Collaborately control of workability for loess mixed with bentonite-HDTMA," Industrial Constructon, vol. 51, pp. 160-165, 2021.

[20] C. D. Maio, L. Santoli, and P. Schiavone, "Volume change behavior of clay: the influence of mineral composition, pore 
fluid composition and stress state," Mechanics of Materials, vol. 36, pp. 435-451, 2010.

[21] W. J. Sun, D. A. Sun, and W. Yan, "Deformation characteristics of unsaturated bentonite under $\mathrm{K} 0$-compression stress state," Journal of Shanghai University (Natural Science Edition), vol. 16, pp. 105-110, 2010.

[22] H. Kawakami, "Shear characteristics of saturated gravelly clays," Transactions of the Japanese Society of Civil Engineers, vol. 2, no. 2, pp. 295-298, 1970.

[23] B. X. Yuan, Z. H. Li, Z. L. Su, Q. Luo, M. Chen, and Z. Zhao, "Sensitivity of multistage fill slope based on finite element model," Advances in Civil Engineering, vol. 2021, pp. 1-13, Article ID 6622936, 2021.

[24] R. B. Gonzalez, R. Trujillano, V. Rives, M. A. Vicente, A. Gil, and S. A. Korili, "Structural, testural and acidic properties of $\mathrm{Cu}$-, Fe- and Cr- doped Ti-pillared montmorillonites," Applied Clay Science, vol. 118, pp. 124-130, 2015.

[25] T. Bajda and Z. Kłapyta, "Adsorption of chromate from aqueous solutions by HDTMA-modified clinoptilolite, glauconite and montmorillonite," Applied Clay Science, vol. 86, pp. 169-173, 2013.

[26] Y. Wu, J. Cui, J. Huang, W. Zhang, N. Yoshimoto, and L. Wen, "Correlation of critical state strength properties with particle shape and surface fractal dimension of clinker ash," International Journal of Geomechanics, vol. 21, no. 6, Article ID 04021071, 2021.

[27] M. M. Ge, N. Li, D. C. Sheng et al., "A microstructural insight on the deformation of unsaturated compacted loess under hydraulic coupling actions," Rock and Soil Mechanics, vol. 9, pp. 1-13, 2021.

[28] B. X. Yuan, M. Sun, L. Xiong, Q. Luo, S. P. Pradhan, and H. Li, "Investigation of 3D deformation of transparent soil around a laterally loaded pile based on a hydraulic gradient model test," Journal of Building Engineering, vol. 28, no. 6, Article ID 101024, 2019.

[29] H. Luo, F. Q. Wu, J. Y. Chang et al., "Pore characteristics of malan loess - a case study of zhaojiaan area loess," Journal of Engineering Geology, vol. 22, pp. 845-850, 2014.

[30] B. Bai, D. Rao, T. Chang, and Z. Guo, "A nonlinear attachment-detachment model with adsorption hysteresis for suspension-colloidal transport in porous media," Journal of Hydrology, vol. 578, Article ID 124080, 2019.

[31] B. X. Yuan, Z. H. Li, Z. Q. Zhao, H. Ni, Z. Su, and Z. Li, "Experimental study of displacement field of layered soils surrounding laterally loaded pile based on Transparent Soil," Journal of Soils and Sediments, vol. 21, pp. 3072-3083, 2021. 